\title{
COLORECTAL CANCER AND LYMPH NODE COUNT: IS THE NUMBER RECOMMENDED FOR STAGING RETRIEVED?
}

\section{Pathology} $\begin{array}{ll}\text { Dr. Suhail Saleem* } & \begin{array}{l}\text { Department of Pathology, Amala Institute of Medical Sciences, Thrissur, Kerala, India. } \\ * \text { Corresponding Author }\end{array}\end{array}$

\section{Dr. Vijayalakshmi Nair \\ Department of Pathology, Amala Institute of Medical Sciences, Thrissur, Kerala, India.} \begin{abstract}
Background: Colorectal cancer (CRC) ranks as the third most commonly diagnosed cancer in males and the second in females. According to the TNM staging system, status of the draining lymph nodes is a key pathologic characteristic. Inadequate lymph node harvesting may result in under treatment of patients. The purpose of the present study was to evaluate the factors that influence the number of lymph nodes retrieved in colorectal cancer specimens.

Methods: Sixty five patients with histologically proven colorectal adenocarcinoma over a period of 18 months were included. All patients underwent surgical resection for their disease. All significant patient, tumour and treatment variables were assessed for their impact on the average total number of lymph node harvested. Further, the efficacy of the GEWF solution (glacial acetic acid, ethanol, distilled water, formaldehyde) in lymph node retrieval was also assessed.

Results: In this study, 43 men and 22 women with a median age of 61 years were included. The median total number of lymph nodes examined was 17. $87.6 \%$ had adequate $(\geq 12)$ lymph nodes examined, and $12.4 \% \mathrm{had}<12$ nodes examined. The number of lymph nodes were found to be higher and statistically significant in under 60 -year-old group $(\mathrm{p}=0.001)$, tumours of size $>5 \mathrm{~cm}(\mathrm{p}=0.002)$, tumours of the ascending colon $(\mathrm{p}=0.025)$ and cases operated on by super specialist surgeons $(p=0.017)$. Factors such as gender $(p=0.23), B M I(p=0.22)$, tumour differentiation $(p=0.348)$ and $T$ staging $(\mathrm{p}=0.026)$ had no statistically significant association with lymph node harvest. Mean LN count was significantly higher $(\mathrm{p}=0.0001)$ regrossing by a senior pathologist. However a statistically significant increase in LN harvest was not seen $(p=0.159)$ when specimens were further subjected to GEWF treatment.

Conclusions: This study indicates that several modifiable factors impact LN retrieval and hence gives scope for improvement. Refinement of surgical and pathological care is suggested especially in challenging cases like rectal cancer and elderly patients.
\end{abstract}

\section{KEYWORDS}

Colorectal Cancer; Lymph Node Staging; GEWF

\section{INTRODUCTION}

Colorectal cancer (CRC) ranks as the third most commonly diagnosed cancer in males and the second in females. In 2012, over 1.4 million new colorectal cancer cases were reported worldwide with an estimated 6, 93,900 deaths (1).

The most commonly used staging system for CRC is the American Joint Committee on Cancer (AJCC) tumour node metastasis (TNM) staging system. According to this system, a key pathologic characteristic in determining the stage of disease in colon cancer is the status of the draining lymph nodes (2). The reason that nodal involvement is such a crucial feature is its impact on a patient's likelihood of long-term cure. The presence of lymph node metastases usually modifies the therapeutic recommendation for a patient, with node positive patients being offered adjuvant chemotherapy.

The number of lymph nodes retrieved from a case of CRC will hence invariably play a pivotal role in accurate staging of the disease. Inadequate lymph node harvesting may result in underestimation of the positive lymph nodes and hence under treatment of patients (3). After years of debate and research, it is now considered that a minimum of 12 lymph nodes have to be harvested to correctly stage colorectal cancer. (4) (5) Despite several such recommendations, inadequate lymph node evaluation is still common. Many clinicopathological factors have been implicated for this inadequacy. Considering the importance of tumour staging and the relevance of lymph node harvest in the assessment of tumour stage, a detailed analysis of the factors with incorporation of possible improvements is the need of the hour.

\section{MATERIALAND METHODS}

This was a descriptive study conducted at the Department of Pathology, Amala Institute of Medical Sciences, a tertiary care centre in South India. A total of 65 confirmed cases of colonic or rectal carcinoma cases were studied.

\section{Inclusion Criteria}

1. Patients with invasive colorectal carcinoma.

\section{Exclusion Criteria}

1. Patients with pathologies other than colorectal carcinoma

2. Patients with unresectable or inoperable disease.
3. Patients who have undergone pre-operative neoadjuvant therapy.

A predesigned clinical proforma was used to document the particulars of the patient relevant to this study. The specimens were received in adequate volume of $10 \%$ formalin which were then cut open and fixed for a minimum period of 24 hours. After fixation, grossing of the specimen was done as per standard protocol. The tumour was then sectioned serially, assessing the depth of tumour infiltration and the serosal and circumferential resection margins wherever applicable. Appropriate selection of the blocks was done after examining the tumour slices where the tumour infiltration in the wall was judged to be maximum. The lymph nodes are then carefully dissected from the pericolic/perirectal fat. The pericolic/perirectal fat was then examined by a senior pathologist for any lymph nodes missed on initial grossing.

The pericolic/perirectal fat was then removed and subjected to fat clearance using the Glacial acetic acid, Ethanol,distilled Water, Formaldehyde (GEWF) solution. It was submerged in approximately 1 L of GEWF (which corresponds to 2-3 volumes of pericolic fat) for 12 to 18 hours. Following GEWF treatment, the pericolic/perirectal fat was examined again for any extra lymph nodes. All lymph nodes, however small, were processed and examined histologically.

For statistical analysis, the data was entered into suitable Excel Worksheets and analysed using IBM SPSS version 16.0 statistical software. All continuous variables were summarized as mean and standard deviation and categorical variables as frequency tables. The variables were evaluated using the independent $t$ test, paired $t$ test and ANOVA. Thep-value for ascertaining statistical significance was set at 0.05 .

\section{RESULTS}

In this study, patients were divided into two groups based on age. The mean number of lymph nodes were found to be significantly higher $(\mathrm{p}=0.001)$ in under 60 -year-old group when compared to older age groups. (Table 1).

Table 1: Comparison Of Mean Lymph Nodes By Age Group

\begin{tabular}{|c|c|c|c|c|c|}
\hline \multirow[t]{2}{*}{ Variables } & \multirow[t]{2}{*}{ Patients } & \multicolumn{2}{|c|}{ Mean total } & $\begin{array}{l}95 \% \text { CI for } \\
\text { Mean's } \\
\text { difference }\end{array}$ & \multirow{2}{*}{ p value } \\
\hline & & $\mathbf{L N}$ & SD & & \\
\hline$\leq 60$ years & 30 & 20.93 & 6.61 & & \\
\hline
\end{tabular}




\begin{tabular}{|l|l|l|l|l|l|l|}
\hline Age & & & & & $3.11-8.41$ & 0.001 \\
\hline & $>60$ years & 35 & 15.17 & 3.89 & & \\
\hline
\end{tabular}

Mean amount of lymph nodes harvested in men was 17.19 and in women was 19.09 respectively. There was no statistically significant difference between gender and lymph node retrieval $(\mathrm{p}=0.23)$ (Table 2).

Table 2: Mean Lymph Nodes Harvested Vs Gender

\begin{tabular}{|l|l|l|l|l|l|l|}
\hline Variable & Patients & \multicolumn{2}{|l|}{ Mean total } & $\begin{array}{l}\text { 95\% CI for } \\
\text { Mean's } \\
\text { difference }\end{array}$ & p value \\
\hline & & & LN & SD & & \\
\hline Gender & Male & 43 & 17.19 & 5.3 & $-5.04-1.24$ & 0.23 \\
\hline & Female & 22 & 19.09 & 7.2 & & \\
\hline
\end{tabular}

Similarly no statistically significant association was seen between BMI and LN harvest. $(\mathrm{p}=0.22)$ (Table 3$)$

Table 3: Mean Lymph Nodes Harvested Vs BMI

\begin{tabular}{|l|l|l|l|l|l|l|}
\hline \multicolumn{2}{|l|}{ Variable } & Patients & \multicolumn{2}{|l|}{ Mean total } & $\begin{array}{l}\text { 95\% CI for } \\
\text { Mean's } \\
\text { difference }\end{array}$ & p value \\
\hline & & & LN & SD & & \\
\hline BMI & $18-22$ & 46 & 17.24 & 6.13 & $-5.29-1.24$ & 0.22 \\
\hline & $23-25$ & 19 & 19.26 & 5.66 & & \\
\hline
\end{tabular}

The influence of tumour size was studied using $5 \mathrm{~cm}$ as the reference. Tumours of size $>5 \mathrm{~cm}$ had a mean LN harvest of 19.48 which was significantly higher $(\mathrm{p}=0.002)$ than that of tumours which measured $\leq$ $5 \mathrm{~cm}$. (Table 4).

Table 4: Mean Lymph Node Harvested Vs Tumour Size

\begin{tabular}{|l|l|l|l|l|l|l|}
\hline \multicolumn{2}{|l|}{ Variable } & Patients & \multicolumn{2}{|l|}{ Mean total } & $\begin{array}{l}\text { 95\% CI for } \\
\text { Mean's } \\
\text { difference }\end{array}$ & \\
\cline { 3 - 7 } & & LN value & SD & \\
\hline Tumour & $>5 \mathrm{~cm}$ & 42 & 19.48 & 6.20 & $1.72-7.57$ & 0.002 \\
\hline size & $\leq 5 \mathrm{~cm}$ & 23 & 14.83 & 4.38 & & \\
\hline
\end{tabular}

When the location of tumour is taken into consideration (Tabe 5), number of lymph node retrieved in the ascending colon was more than those in other sites, which was found to be statistically significant $(p=0.025)$.

Table 5: Mean Lymph Node Harvested Vs Tumour Location

\begin{tabular}{|l|l|l|l|l|l|l|}
\hline Variable & Patients & \multicolumn{2}{|l|}{ Mean total } & $\begin{array}{l}\text { 95\% CI for } \\
\text { Mean's } \\
\text { difference }\end{array}$ & p value \\
\cline { 3 - 6 } & & LN & SD & & \\
\hline Location & A colon & 18 & 21.39 & 7.1 & $16.33-19.32$ & 0.025 \\
\cline { 2 - 5 } & D colon & 6 & 17.67 & 5.39 & & \\
\cline { 2 - 5 } & Sigmoid & 13 & 16.54 & 4.48 & & \\
\cline { 2 - 5 } & Rectum & 28 & 16.18 & 4.27 & & \\
\hline
\end{tabular}

The length of specimens was also compared with the number of lymph nodes retrieved (Table 6).

Table 6: Mean Lymph Node Count Vs Specimen Length

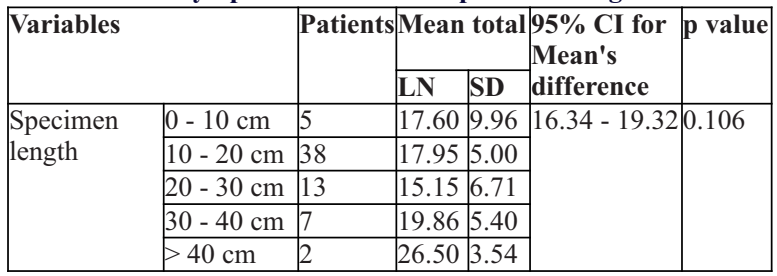

This comparison did not show any significant change in LN harvest with variation in specimen length. Lymph node retrieval in welldifferentiated tumours was less than in moderately differentiated tumours. However this result was not statistically significant $(\mathrm{p}=0.348)$. $($ Table 7$)$.

Table 7: Mean Lymph Node Count Vs Tumour Grade

\begin{tabular}{|l|l|l|l|l|l|l|}
\hline Variables & Patients & $\begin{array}{l}\text { Mean } \\
\text { total }\end{array}$ & \multicolumn{2}{l}{$\begin{array}{l}\text { 95\% CI for } \\
\text { Mean's } \\
\text { difference }\end{array}$} & p value \\
\cline { 3 - 6 } & & LN & SD & \\
\hline $\begin{array}{l}\text { Tumour } \\
\text { grade }\end{array}$ & $\begin{array}{l}\text { Well differentiated } \\
\text { differen }\end{array}$ & 25 & 16.76 & 4.95 & $16.33-19.32$ & 0.348 \\
\hline
\end{tabular}

\begin{tabular}{|l|l|l|l|}
\hline $\begin{array}{l}\text { Moderately } \\
\text { differentiated }\end{array}$ & 39 & 18.64 & 6.60 \\
\hline $\begin{array}{l}\text { Poorly } \\
\text { differentiated }\end{array}$ & 1 & 13.00 & \\
\hline
\end{tabular}

T staging was done in patients with CRC. The number of lymph nodes retrieved in patients with $\mathrm{T} 3$ and $\mathrm{T} 4$ was more than in patients with $\mathrm{T} 1$ and T2. However there was no statistically significant difference between $\mathrm{T}$ staging and lymph node retrieval $(\mathrm{p}=0.026)$ (Table 8).

\begin{tabular}{|c|c|c|c|c|c|c|}
\hline \multirow{2}{*}{\multicolumn{2}{|c|}{ Variables }} & \multirow[t]{2}{*}{ Patients } & \multicolumn{2}{|c|}{ Mean Total } & \multirow{2}{*}{$\begin{array}{l}95 \% \text { CI } \\
\text { for Mean's } \\
\text { difference }\end{array}$} & \multirow{2}{*}{ p value } \\
\hline & & & \begin{tabular}{|l|}
$\mathbf{L N}$ \\
\end{tabular} & \begin{tabular}{|l|} 
SD \\
\end{tabular} & & \\
\hline \multirow{2}{*}{$\begin{array}{l}\text { Primary } \\
\text { tumour stage }\end{array}$} & $\mathrm{T} 1$ and $\mathrm{T} 2$ & 19 & 16.84 & 5.82 & \multirow[t]{2}{*}{$-4.69-1.89$} & \multirow[t]{2}{*}{0.399} \\
\hline & T3 and T4 & 46 & 18.24 & 6.12 & & \\
\hline
\end{tabular}

Thirteen patients were operated on by general surgeons. The mean amount of lymph nodes harvested was 14.31. Specialist surgeons operated on 52 patients. The mean amount of lymph nodes was 18.71 , and this difference was statistically significant $(\mathrm{p}=0.017)$ (Table 9).

Table 9: Mean Lymph Node Count Vs Operating Surgeon

\begin{tabular}{|c|c|c|c|c|c|c|}
\hline \multirow{2}{*}{\multicolumn{2}{|c|}{ Variable }} & \multirow[t]{2}{*}{ Patients } & \multicolumn{2}{|c|}{ Mean Total } & \multirow{2}{*}{$\begin{array}{l}95 \% \text { CI } \\
\text { for } \\
\text { Mean's } \\
\text { difference }\end{array}$} & \multirow{2}{*}{ p value } \\
\hline & & & $\mathbf{L N}$ & SD & & \\
\hline \multirow[t]{2}{*}{ Surgeon } & General Surgeon & 13 & 14.31 & 3.92 & \multirow{2}{*}{$\begin{array}{l}-7.99-- \\
0.81\end{array}$} & \multirow[t]{2}{*}{0.017} \\
\hline & \begin{tabular}{|l|} 
Specialist \\
Surgeon
\end{tabular} & 52 & 18.71 & 6.16 & & \\
\hline
\end{tabular}

Quality of pathological care was assessed by successive grossing of specimens by a junior pathologist and then a senior pathologist. The extra lymph nodes harvested by the senior pathologist are added to the tally of lymph nodes harvested by the junior pathologist. This is under the assumption that the senior pathologist would have retrieved the extra lymph nodes in addition to the ones harvested by the junior had the senior pathologist grossed first. It was observed that the mean LN count after initial grossing by a junior pathologist was only 11.38 but it increased to 16.37 upon re-grossing by a senior pathologist. The mean difference was 4.98 , i.e. on an average, 4.98 extra LNs were being retrieved by the senior pathologist on re-grossing, which is statistically significant. (Table 10) Efficacy of enhancement techniques, with GEWF being used in the current study was also assessed by the same successive grossing technique.

Table 10: Mean Lymph Node Count: Junior Pathologist Vs Senior Pathologist

\begin{tabular}{|l|l|l|l|l|l|}
\hline Groups & Mean & SD & $\begin{array}{l}\text { 95\% Confidence Interval for } \\
\text { Mean value }\end{array}$ & \\
\cline { 3 - 5 } & & Lower Bound & Upper Bound & \\
\hline $\begin{array}{l}\text { LN harvest by } \\
\text { junior Doctor }\end{array}$ & 11.38 & 5.53 & 10.01 & 12.76 & 0.0001 \\
\hline $\begin{array}{l}\text { LN harvest by } \\
\text { senior Doctor }\end{array}$ & 16.37 & 5.75 & 14.95 & 17.79 & \\
\hline
\end{tabular}

The specimens which were grossed by the junior and senior pathologists were then subjected to GEWF treatment and a search for extra LNs was made. Hence a comparison was being made between LNs harvested by manual dissection alone and following the use of visual enhancement techniques. However, data shows that a statistically significant increase in LN harvest was not seen. (Table11).

Table 11: Mean Lymph Node Count: Manual Dissection Vs GEWF Solution

\begin{tabular}{|l|l|l|l|l|l|}
\hline Groups & Mean & SD & $\begin{array}{l}\text { 95\% Confidence Interval for } \\
\text { Mean }\end{array}$ & value \\
\cline { 3 - 5 } & & Lower Bound & Upper Bound & \\
\hline $\begin{array}{l}\text { LN harvest } \\
\text { by manual } \\
\text { dissection }\end{array}$ & 16.37 & 5.75 & 14.95 & 17.79 & 0.159 \\
\hline $\begin{array}{l}\text { LN harvest } \\
\text { after GEWF } \\
\text { treatment }\end{array}$ & 17.83 & 6.02 & 16.37 & 19.29 & \\
\hline
\end{tabular}

The excess LNs discovered following grossing by senior pathologist and GEWF treatment were assessed for evidence of metastasis. The mean positive lymph nodes rose from 1.4 to 1.9 following re-grossing by the senior pathologist (Table 12). This further increased marginally to 1.93 following GEWF treatment (Table 13). However this rise in positive lymph nodes were not statistically significant. 
Table 12: Mean Positive Lymph Node Count: Junior Pathologist Vs Senior Pathologist

\begin{tabular}{|l|l|l|l|l|l|}
\hline Groups & Mean & SD & \multicolumn{2}{|l|}{$\begin{array}{l}\text { 95\% Confidence Interval } \\
\text { for Mean }\end{array}$} & p value \\
\cline { 3 - 6 } & & Lower Bound & Upper Bound & \\
\hline $\begin{array}{l}\text { Positive LN } \\
\text { harvest by } \\
\text { junior Doctor }\end{array}$ & 1.40 & 2.70 & 2.05 & 3.35 & 0.478 \\
\hline $\begin{array}{l}\text { Positive LN } \\
\text { harvest by } \\
\text { senior Doctor }\end{array}$ & 1.90 & 3.56 & 2.7 & 4.42 & \\
\hline
\end{tabular}

Table 13: Mean Positive Lymph Node Count: Manual Dissection Vs GEWF Solution

\begin{tabular}{|l|l|l|l|l|l|}
\hline Groups & Mean & SD & $\begin{array}{l}\text { 95\% Confidence Interval } \\
\text { for Mean }\end{array}$ & p value \\
\cline { 3 - 5 } & Lower Bound & Upper Bound & \\
\hline $\begin{array}{l}\text { Positive LNs in } \\
\text { harvest by } \\
\text { manual } \\
\text { dissection }\end{array}$ & 1.90 & 3.56 & 2.7 & 4.42 & 0.988 \\
\hline $\begin{array}{l}\text { Positive LNs in } \\
\text { harvest after } \\
\begin{array}{l}\text { GEWF } \\
\text { treatment }\end{array}\end{array}$ & 1.93 & 3.62 & 2.74 & 4.5 & \\
\hline
\end{tabular}

\section{DISCUSSION}

Proper staging of primary colorectal carcinoma is of prime importance in assessment of prognosis as well as for treatment. Harvesting adequate number of lymph nodes (LNs) from a colorectal specimen is an essential part of this process. Positive lymph nodes are the main criterion to determine the need for adjuvant chemotherapy (3). Inadequate lymph node assessment is associated with poorer outcome in terms of tumour recurrence and patient survival. Infact, patients labelled lymph node negative on the basis of a low lymph harvest are deemed as being at high risk of recurrence by some authors and thus are ideal candidates for adjuvant therapy (6). The low lymph node harvest is likely to be an indicator of poor quality surgical or pathologic care.

After much debate, various organisations like the National Comprehensive Cancer Network (NCCN), the American Association of Clinical Oncology (ASCO) and the American College of Surgeons have now endorsed 12 as the minimal number of LNs that have to be harvested for optimal staging (4) (5) (7). Though there have been conflicting reports about this number, like Cianchi et al. who states that 9 LNs are sufficient (8), the vast majority of pathologists agree on the number 12

The current study demonstrated a mean lymph node retrieval of 17.83 which was considerably higher than the mean in most of the available literature. The percentage of cases without adequate lymph node harvest was also significantly low. Out of the 65 cases in this study, only 8 cases had a LN harvest of less than 12 which accounts for only $12.3 \%$ of cases [Figure 10 ].

However, literature shows that in spite of all the advancements in this field, this minimum number of LNs is still not achieved in all cases. Recent data from the United States show that lymphadenectomy is inadequate in $48 \%$ to $63 \%$ of cases (9). Studies by Johnson et al. and Mitchell et al. on CRC cases in the United Kingdom also demonstrated a deficit in LN harvest in 33\% and 50\% cases, respectively. (10) (11). This variability has been explained to be due to the interplay of various factors relating to the patient, tumour and quality of care.

\section{Patient Factors}

Age

Age is an important determinant of LN yield. Our study found that the age of the patient affected lymph node retrieval $(\mathrm{p}=0.001)$ [Table 1]. The mean number of LNs harvested from colorectal cancer patients $\leq$ 60 years of age was 20.93 and $>60$ years was 15.17 respectively.

Reduction in LN harvest with age is an established finding by almost all authors. With 50 years as the reference age, Ghahramani et al. showed that the mean $L N$ retrieval was 11.11 and 8.27 in patients aged $<50$ and $>50$ respectively (36). Norwood et al., Chou et al. and Hakki et al. also showed similar trends in their observations (12) (13) (14).

Gender

The current study did not find any statistically significant correlation between mean lymph node count and gender of the patient. Though the mean LNs harvested is more in females (19.09), the difference in LN harvest between the two genders was not found to be statistically significant [Table 2]

Reports in the literature are also conflicting thereby rendering a doubtful role for sex of the patient on lymph node harvest. While most authors claim that sex of the patient is unlikely to be a parameter (12) (14), there are some others like Fan et al. and Chenet al. who mention greater sampling in females (15) (16). However they report very low statistical significance and hence are of doubtful clinical relevance.

\section{BMI}

With latest data considering 23 as the cut off for BMI for the Asian population, cases in the present study were classified into groups based on the above reference value. Upon calculation of mean lymph node count for the two groups, no significant difference was observed $(\mathrm{p}=0.22)$ [Table 3$]$ thereby arriving at the conclusion that BMI had no role to play in lymph node harvest.

However, this result is contradictory to the results obtained by a majority of authors like Kuo et al. and Shibakita et al. (17) (18) who have specifically studied the effect of BMI alone on LN harvest. They showed a lower harvest in patients with high BMI. This difference has been postulated by some authors to be due to a more difficult surgical dissection in obese individuals. (6) (7)

\section{Tumour Factors}

\section{Tumour Size}

Size of the tumour is undoubtedly an important factor determining LN retrieval. It is believed that larger tumours elicit a stronger immune response and hence make the LNs more visible to the naked eye (19). In agreement with this hypothesis, our study showed a similar trend. Tumours of size $\leq 5 \mathrm{~cm}$ had a mean LN harvest of 14.83 which was considerably less than tumours measuring more than $5 \mathrm{~cm}$ (Mean LN19.48). With a $\mathrm{p}$ value of 0.002 , tumour size does indeed play a statistically significant role in LN harvest [Table 4].

Chou et al. had also observed a specific $2 \%$ increase in LNs for every 1 $\mathrm{cm}$ increase in tumour size (13). Similarly, Mekenkamp et al. observed an increase in LN harvest by 3 nodes between tumours measuring $<2 \mathrm{~cm}$ and $2-5 \mathrm{~cm}$ and by a further 3 nodes from $2-5 \mathrm{~cm}$ and $>5 \mathrm{~cm}(20)$.

\section{Tumour Location}

With regard to tumour location, our study obtained results that conformed to the literature. Right sided colon cancers had a mean 21.39 LNs harvested against 17.10 for left sided tumours (tumours in the descending colon and sigmoid colon combined)which was statistically significant $(\mathrm{p}=0.025)$. [Table 5]

In CRC cases with primary tumour in the colon, Baxter et al. reported that patients with right sided lesions had adequate LN harvests unlike patients with left sided disease (21).

Wright et al. observed that a median number of 12 LNs and 9 LNs were harvested for the right and left colon, respectively (22).

Though our study had maximum patients with primary in the rectum $(n=28)$, the mean number of LNs harvested is 16.18 which was the least compared to all other sites. Our result complies with data from literature and could possibly be explained by the difficulty in retrieving LNs rectal cancers due to the smaller size of the LNs (23). Hence tumour location is a very important factor determining lymph node harvest.

\section{Specimen length}

It has been postulated that since the ascending colon is longer than other parts of the colon, the increased length of the specimen might be one of the reasons why more lymph nodes were harvested in the right sided tumours of the colon. However in the current study, though a greater number of lymph nodes were harvested in the ascending colon, specimen length did not show a statistically significant association with lymph node count thereby refuting the postulation. Data did show an increase in LN harvest with increase in length, but was insignificant $(\mathrm{p}=0.106)$ [Table 6].

However studies by authors on this matter have shown specimen length to have a significant impact on LN harvest. Wright et al. and Johnson et al. found a statistically significant correlation between the 
length of the specimen and lymph node retrieval giving more weight to the above hypothesis (22) (24). Hakki et al. too obtained similar results thereby further substantiating the positive correlation between specimen length and LN harvest (14).

\section{Tumour Grade}

CRC cases are graded as well differentiated, moderately differentiated and poorly differentiated based on their differentiation, i.e. their level of resemblance to the normal histology. In our study, the maximum cases were of moderate differentiation $(n=39)$ with a mean $L N$ count of 18.64. This was followed by well differentiated carcinomas which had a mean $16.76 \mathrm{LNs}$ harvested. Only one poorly differentiated carcinoma was obtained in the study. Since the p value was statistically calculated to be 0.348 , the difference in mean LN count was concluded to be insignificant. [Table 7].

This was however contrasting to the results obtained by Hakki et al. They found lymph node retrieval in tumours with well-differentiated cancers to be less than in tumours with poorly differentiated cancers (14).Several others too reported a similar tendency notably Baxter et al. and Lee et al. (21) (25)

\section{Tumour stage}

As it is expected, all authors report that as tumour stage progresses from T1 to T4, lymph node retrieval increases. Even in the present study, the mean number of LNs retrieved in patients with T3 and T4 stage tumours were more than in patients with $\mathrm{T} 1$ and $\mathrm{T} 2$ tumours. Despite the increase, it was not statistically significant. [Table 8]

Reports in the literature are both compliant and contradictory to the present study. While some authors like Wright et al. (22) obtained similar results as the present study, others like Chou et al. (13) demonstrated a stark contrast. Baxter et al. went on to try and find the reason for this trend but in vain (21). Thus, this issue calls for more investigation

\section{Modifiable Factors \\ Surgeons And Surgery}

Surgeon's experience and specialisation are two important parameters that adjudge the quality of surgical care which can directly affect LN harvest. Existing literature supports the assumption that quality of surgery influences the number of nodes harvested. Even our study raises valid questions regarding the significance of surgical training in relation to the lymph node harvest in resected specimens. Statistically significant difference in LN harvest was seen in cases operated on by general surgeons and specialist surgeons. Mean LN harvest in CRC cases operated by surgeons with superspeciality training was 18.71 compared to 14.31 in cases operated by general surgeons. This is a significant difference $(\mathrm{p}=0.017)$ which could be due to the greater radicality of surgery performed by superspecialist surgeons [Table 9].

A higher average nodal harvest in CRC cases operated by surgeons with a specialisation training was reported by Johnson et al. (24). However a consensus cannot be reached with this data, as studies in the UK have shown no statistically significant difference in lymph node harvest between general and specialist surgeons (12).

\section{Pathologists}

Among the modifiable factors, literature shows that the influence of pathologist is much greater than that of the surgeon (79). The present study aimed to assess the influence of pathological expertise on lymph node retrieval. For this, the specimens initially grossed by a junior pathologist were re-grossed by a senior pathologist. It was observed that following lymph node harvest by the senior pathologist, there was an increase in mean LN count by 4.98 [Table 10]. This is a significant value which highlights the importance of experience beyond doubt.

Studies from different parts of the world like Mekenkamp et al. from Netherlands, Thorn et al. from UK and Reiger et al. from Australia also report dissimilarities between pathologists harvesting LNs that were significant statistically (20) (26) (27). These studies prove that meticulousness of the pathologist and allied staff can go a long way in improving LN harvest. Ostadi et al. cited that out of all the factors affecting LN harvest, it is the quality of pathological care which is the most important determinant of LN harvest (23). Johnson et al. found that specimens that underwent gross examination by a staff pathologist had more lymph nodes identified than those retrieved by pathology residents (24).

Pathological Techniques To Increase Nodal Yield

As stated earlier, the quality of pathological care is perhaps the most important determinant of LN retrieval. Hence it is imperative to employ methods or techniques to increase the efficiency of the pathologist in $\mathrm{LN}$ harvest. Techniques involving highlighting of lymph nodes, collectively called 'visual enhancement techniques' have been tried with mixed results. Starting with Gilchrist et al. in 1938 (28) with the use of alcohol, different solutions like xylene, acetone etc. have been tried by researchers with mixed results.

The GEWF solution used in this study was first used by Koren et al. in 1997 following which it gained a lot of attention (29). Being relatively free of toxic side effects, we had favoured the use of this solution over several others in our study. Following manual dissection, a repeat examination for any missed LNs revealed an increase in mean LN count by 1.47 , but this increase was not statistically significant [Table11]. Hence, we arrived at the conclusion that a thorough manual dissection is in fact superior to the use of visual enhancement techniques in the retrieval of lymph nodes.

GEWF solution has met with mixed results in different studies. The effectiveness of this solution was demonstrated by Newell et al. in their exhaustive study which showed a definite increase in $\mathrm{LN}$ harvest with the use of GEWF solution. A mean increase of $10.2 \pm 4.9$ per case for GEWF vs $6.8 \pm 3.9$ per case for non-GEWF was observed (30). Though their work was comprehensive their results were not definitive as contradictory reports are present in literature. Gregurek et al. and Abbassi-Ghadi et al. differed with Newell et al. and arrived at the conclusion that these techniques were not particularly useful (31) (32). With the discovery of missed lymph nodes either by the senior pathologist or following GEWF treatment, a search for evidence of metastasis was made in the extra lymph nodes. This could upstage the tumours thereby even changing their treatment protocol. Our study showed that the mean positive lymph node count rose from 1.4 to 1.9 following grossing by the senior pathologist (Table 12). The mean difference of 0.5 is however insignificant. Similarly the mean positive lymph node count rose by a trivial 0.03 to 1.93 following lymph node retrieval after subjecting the specimens to GEWF which was also statistically insignificant (Table 13).

A similar inference can be drawn from the pioneering work done with GEWF solution by Newell et al. and Gregurek et al. They found that, though the number of lymph nodes retrieved with evidence of metastasis was higher following GEWF treatment, this increase was not statistically significant (30) (31)

\section{CONCLUSION}

The current study established that LN harvest from CRC surgical specimens depends on various patient, tumour and clinico-pathologic factors. This study indicates that lymph node retrieval was not affected by gender, BMI, specimen length, tumour stage and tumour differentiation. However, there are several parameters that play a noteworthy role in $\mathrm{LN}$ harvest. Age is the only significant patient factor that has an impact on LN harvest. As far as tumour parameters are concerned, tumour location and tumour size are significant determinants. Though the above are non-modifiable factors, the modifiable factors also have a significant impact on $L N$ retrieval which thereby gives scope for improvement and increase staging accuracy and overall prognosis. Surgical specialist training can cause a profound increase in LN harvest. The significance of quality of pathological care and experience of the pathologist has also been stressed. All of these factors are likely to be more or less accountable for $\mathrm{LN}$ harvest. $\mathrm{LN}$ retrieval in primary rectal cancer continues to be a challenge, as does LN harvest in elderly patients. Unending emphasis should be employed on improving quality of surgical and pathologic care to improve overall $\mathrm{LN}$ yields.

\section{REFERENCES}

. Ferlay J, Soerjomataram I, Ervik M, Dikshit R, Eser S, Mathers C, Rebelo M, Parkin DM, Forman D, Bray F. GLOBOCAN 2012 v1.1, Cancer Incidence and Mortality Worldwide: IARC Cancer Base No. 11 . Lyon, France: International Agency for Rerearch on Concer; 2014. [Online][Cited: 10 November 2015.] http:/globoncy for Researchr, Concer. Byrd DR, Compton CC, Joint Committee on Cancer,AJCC Cancer Staging Manual. New York: Springier, 2010,p. 143.

3. Chang GJ, Rodriguez-Bigas MA, Skibber JM, Moyer VA. Lymph node evaluation and survival after curative resection of colon cancer: systematic review. J Natl Cancer Inst. 2007, Vol. 99, pp. 433-41.

4. NCCN.http://www.nccn.org/professionals/quality_measures/PDF/colon_quality measures.pdf.[Online]

National Quality Forum. http://www.qualityforum.org/pdf/cancer/txAppASpecifications_web.pdf. [Online]

6. Prandi M, Lionetto R, Bini A, Francioni G, Accarpio G, Anfossi A, et al. Prognostic evaluation of stage B colon cancer patients is improved by an adequate lymphadenectomy: results of a secondary analysis of a large scale adjuvant trial. Ann lymphadenectomy: results of a secon. 
7. FACS. http://www.facs.org/cancer/qualitymeasures.html. [Online]

8. Cianchi F, Palomba B, Boddi V et al. Lymph node recovery from colorectal tumor specimens: recommendation for a minimum number of lymph nodes to be examined. specimens: recommendation for a minim
World J Surg. 2002, Vol. 26, pp. 384-389.

9. Nathan H, Shore AD, Anders RA, Wick EC, Gearhart SL, Pawlik TM. Variation in lymph node assessment after colon cancer resection: patient, surgeon, pathologist, or hospital? J Gastrointest Surg. 2011, Vol. 15, pp. 471-479

10. Johnson A, Rees JR, Schwenn M, Riddle B, Verrill C,Celaya MO, Nicolaides DA, Cherala S, Feinberg M, Gray A, Rutstein L, Katz MS, Nunnink JC. Oncology care in rural Northern New England. J Oncol Pract. 2010, Vol. 6, pp. 81-89.

11. Mitchell PJ, Ravi S, Grifftiths B, Reid F, Speake D, Midgley C, Mapstone N.Multicentre review of lymph node harvest in colorectal cancer: are we understaging colorectal cancer patients? Int J Colorectal Dis. 2009, Vol. 24, pp. 915-921.

12. Norwood MG, Sutton AJ, West K, Sharpe DP, Hemingway D, et al. Lymph node retrieval in colorectal cancer resection specimens: national standards are achievable, and low numbers are associated with reduced survival. Colorectal Dis. 2010, Vol. 12, pp. 304-309.

13. Chou JF, Row D, Gonen M, Liu YH, Schrag D, Weiser MR. Clinical and pathologic factors that predict lymph node yield from surgical specimens in colorectal cancer: a population-based study. Cancer. 2010, Vol. 116, pp. 2560-2570.

14. Hakk1 I, Ersoz N, Yağc1 G, Can MF, Altınel Ö, Öztürk E, Kurt B, Harlak A,Duran E, Peker Y, Çetiner S. Factors affecting the number of lymph nodes in specimens resected for colorectal cancer. Gülhane Tip Derg. 2013, Vol. 55, pp. 7-13.

15. Fan L, Levy M, Aguilar CE, Mertens RB, Dhall D, Frishberg DP, Wang HL.Lymph node Fan L, Levy M, Aguilar CE, Mertens RB, Dhall D, Frishberg DP, Wang HL.Lymph node
retrieval from colorectal resection specimens for adenocarcinoma: is it worth the extra retrieval from colorectal resection specimens for adenocarcinoma: is it wo
effort to find at least 12 nodes? Colorectal Dis. 2011, Vol. 13, pp. 1377-1383.

16. Chen SL, Steele SR, Eberhardt J, Zhu K, Bilchik A, Stojadinovic A. Lymph node ratio as a quality and prognostic indicator in stage III colon cancer. Ann Surg.2011, Vol. 253, pp. 82-87.

17. Kuo YH, Lee KF, Chin CC, Huang WS, Yeh CH, Wang JY. Does body mass index impact the number of $\mathrm{LNs}$ harvested and influence long-term survival rate in patients with stage III colon cancer? Int J Colorectal Dis. 2012, Vol. 27, pp. 1625-1635.

18. Shibakita M, Yoshimura H, Tachibana M, Ueda S, Nagasue N. Body mass index influences long-term outcome in patients with colorectal cancer. Hepatogastroenterology. 2010, Vol. 57, pp. 62-69.

19. Fielding LP, Arsenault PA, Chapuis PH, Dent O,Gathright B, Hardcastle JD et al. Clinicopathological staging for colorectal cancer: an International Documentation System (IDS) and an International Comprehensive Anatomical Terminology (ICAT). J Gastroenterol Hepatol. 1991, Vol. 6, pp. 325-344.

20. Mekenkamp LJ, van Krieken JH, Marijnen CA, van de Velde CJ, Nagtegaal ID. Lymph node retrieval in rectal cancer is dependent on many factors-the role of the tumor, the patient, the surgeon, the radiotherapist, and the pathologist. Am J Surg Pathol. 2009, Vol. 33, pp. $1547-1553$

21. Baxter NN, Virnig DJ, Rothenberger DA, Morris AM,Jessurun J, Virnig BA. Lymph node evaluation in colorectal cancer patients: a population-based study. J Natl Cancer Inst. 2005, Vol.97, pp. 219-225.

22. Wright F, Law C, Last L, Khalifa M, Arnaout A, Naseer Z. Lymph node retrieval and assessment in stage II colorectal cancer: a population-based study. Ann Surg Oncol. 2003, Vol. 10, pp. 903-909

23. Ostadi MA, Harnish JL, Stegienko S, et al. Factors affecting the number of lymph nodes retrieved in colorectal cancer specimens. Surg Endosc. 2007, Vol.21, pp. 2142-2146

24. Johnson PM, Malatjalian D, and Porter GA. Adequacy of nodal harvest in colorectal cancer: a consecutive cohort study. J Gastrointest Surg. 2002, Vol. 6, pp. 883-888.

25. Lee S, Hofmann LJ, Davis KG, Waddell BE. Lymph node evaluation of colon cancer and its association with improved staging and survival in the Department of Defense Health Care System. Ann Surg Oncol. 2009, Vol. 16, pp. 3080-3086.

26. Thorn CC, Woodcock NP, Scott N, Verbeke C, Scott SB, Ambrose NS. What factors affect lymph node yield in surgery for rectal cancer? Colorectal Dis. 2004, Vol. 6, pp. 356-361

27. Rieger NA, Barnett FS, Moore JW, et al. Quality of pathology reporting impacts on lymph node yield in colon cancer. J Clin Oncol. 2007, Vol. 25, p. 463.

28. Gilchrist R, David V. Lymphatic spread of carcinoma of the rectum. Ann Surg. 1938, Vol. 108, pp. 621-642

29. Koren R, Siegal A, Klein B, et al. Lymph node revealing solution: a prospective study on 35 patients with colorectal cancer. Acta Medica Iranica. 2002, Vol. 40, pp. 223-225. Lillie RD, Fullmer HM. Histopathologic Technic and Practical Histochemistry. 4th. Lillie RD, Fullmer HM. Histopathologic Technic and Practical Histochemistry. 4th.
New York: McGraw-Hill Book Co, 1976

30. Newell KJ, Sawka BW, Rudrick BF, Driman DK. GEWF solution. Arch. Pathol Lab. Med. 2001, Vol. 125, pp. 642-645.

31. Gregurek SF, Wu HH. Can GEWF solution improve the retrieval of lymph nodes from colorectal cancer resections? Arch Pathol Lab Med. 2009, Vol. 133, pp. 83- 86.

32. Abbassi-Ghadi N, Boshier PR, Goldin R, Hanna GB et al. Techniques to increase lymph node harvest from gastrointestinal cancer specimens: a systematic review and metaanalysis. Histopathology. 2012, Vol. 61, pp. 531-542. 